\title{
CHĂM SÓC THIẾT YẾU SỚM CHO TRẺ SINH NON TẠI KHU CÁCH LY DỊCH COVID-19
}

Trần Thị Hoàng, Huỳnh Thị Lệ

Bệnh viện Phụ sản-Nhi Đà Nã̃ng

\begin{abstract}
TÓM TẮT
Đại dịch COVID- 19 đang làm thay đổi nhiều thực hành chăm sóc y tế trên toàn thế giới, nhiều quy trình được đưa ra nhằm phòng chống dịch bệnh. Trẻ sơ sinh, đặc biệt là trẻ sinh non cần được chăm sóc phù hợp ngay từ những phút đâu sau sinh. Khuyến cáo của Tổ chức $Y$ tế thế giới là duy trì cái ôm đâu tiên ngay sau sinh, chăm sóc trẻ bằng phương pháp Kangaroo để hạn chế tối đa các biến chứng bệnh tật và tử vong. Trong bối cảnh có nhiều người về từ vùng dịch tễ COVID-19 là các sản phụ; quá trình sinh và chăm sóc trẻ sớ sinh phải tuân thủ nguyên tắc phòng ngừa COVID-19 do đó việc thực hiện quy trình chăm sóc thiết yếu cho bà mẹ và trẻ sơ sinh trở nên khó khăn. Bài báo này nhằm chia sẻ cách thực hiện chăm sóc thiết yếu trẻ sơ sinh non tháng trong khu cách ly, đặc biệt quy trình chăm sóc điều trị cụ thể một trẻ sinh non 28 tuân 3 ngày, nặng 1035 gram được sinh ra từ khu cách ly Bệnh viện Phụ sản-Nhi Đà Nãng được đặt tiếp xúc da kề da với mẹ, hỗ trợ thở CPAP, ăn sữa mẹ, và chăm sóc bằng phương pháp Kangaroo. Tất cả quy trình chuẩn bị, chăm sóc, điều trị đảm bảo nguyên tắc thực hành trong khu vực cách ly do bệnh lý COVID-19. Đồng thời, bài báo cũng trình bày tóm tắt một số thông tin quan trọng liên quan đến COVID-19 ở bà mẹ và trẻ sơ sinh.
\end{abstract}

\section{ABSTRACT \\ EARLY ESSENTIAL CARE FOR PREMATURE BABY AT THE ISOLATION AREA OF COVID-19 PANDEMIC}

The COVID-19 pandemic has been changing health care practices over the world, with many strict measures and protocols being introduced for preventing this disease. Neonates, especially premature ones, should be cared for appropriately in the first minutes after birth. The World Health Organization has recommended that to maintain the first embrace, Kangaroo Mother Care should be initiated to minimize neonatal morbidity and mortality. In Vietnam, there have been many pregnant women returning from overseas, and the perinatal care process in quaratine areas becomes difficult to implement while following strict infection control guidelines for COVID-19. This paper aims to describe the detailed protocol to care for preterm newborns in a quarantine area, especially to describe the care of a preterm babies born at 28 weeks 3 days, with birth weights of 1035 grams in Da Nang Hospital for Women and Children. The newborns have received skin-to-skin contact with the mother as well as CPAP support, breastfeeding and Kangaroo Mother Care. All of the care and treatment maintained the principles of practice in the QUARANTINE areas for COVID-19. The paper also provides information on COVID-19 in pregnancy and newborns.

Nhận bài: 5-1-2021; Chấp nhận: 10-2-2021

Người chịu trách nhiệm chính: Trần Thị Hoàng

Địa chỉ: Bệnh viện Phụ sản - Nhi Đà Nắng 


\section{1. ĐẶT VẤN ĐỀ}

COVID-19 được xem là thảm họa y tế toàn cầu, bệnh lây truyền nhanh chóng và gây tử vong cao trên toàn thế giới. Đại dịch đang làm thay đổi nhiều thực hành chăm sóc $y$ tế với nhiều quy trình mới được áp dụng nhằm đảm bảo phòng ngừa lây lan. Lĩnh vực chăm sóc bà mẹ và trẻ em cũng đối mặt với nhiều thách thức trong thực hiện nhiệm vụ kép nhằm đảm bảo sự chăm sóc tối ưu cho bà mẹ và trẻ sơ sinh, đồng thời đảm bảo an toàn trong đại dịch COVID-19.

Bằng chứng khoa học cho thấy đa số phụ nữ mang thai nhiễm SARS-CoV-2có triệu chứng nhẹ. Tuy vậy, tỷ lệ sinh non và đòi hỏi nhập vào các đơn vị hồi sức tích cực có thể cao hơn các sản phụ không mắc COVID-19[1]. Bên cạnh đó, phần lớn các khảo sát báo cáo không có sự hiện diện của virus SARS-CoV-2trong nước ối, dây rốn, dịch âm đạo, sữa mẹ, hay dịch hầu họng của trẻ ngay sau sinh [2, 3]. Tổng hợp 50 nghiên cứu trên 714 sản phụ nhiễm SARS-CoV-2 và 606 trẻ sơ sinh, trong đó có 20 trẻ nhiễm SARS-CoV-2, 3 trẻ xét nghiệm có hiện diện SARS-CoV-2 $\operatorname{lgG}$ và lgM, 8 mẫu mô bánh nhau dương tính và 1 mẫu dịch ối dương tính[4]. Điều này cho thấy COVID-19 có thể lây truyền dọc từ mẹ sang thai nhi nhưng rất hiếm xảy ra. Trẻ sơ sinh bị lây nhiễm thường do tiếp xúc với người mẹ hoặc người chăm sóc mắc bệnh $[5,6]$.

Thời điểm dịch COVID-19 bùng phát tại Vũ Hán, khuyến cáo từ Trung Quốc và một số nơi cho rằng nên cách ly trẻ sơ sinh khỏi mẹ ngay sau sinh để phòng ngừa lây truyền do tiếp xúc từ mẹ sang con [7, 8]. Tuy vậy, nghiên cứu gần đây cho thấy nguy cơ lây nhiễm ít hơn ở trẻ em, và khi trẻ nhiễm SARS-CoV-2 thể bệnh thường nhẹ $[9,10]$. Trong khi đó, việc cách ly trẻ sơ sinh khỏi bà mẹ không những gây sang chấn về tâm lý cho mẹ mà còn ảnh hưởng đến quy trình chăm sóc sơ sinh thiết yếu sớm dẫn đến tăng nguy cơ tử vong và bệnh tật ở trẻ sơ sinh[11]. Do đó, việc cách ly chỉ nên được thực hiện khi mẹ hoặc trẻ trong tình trạng nặng cần nhập vào đơn vị hồi sức tích cực. Nghiên cứu gần đây từ Hoa Kỳ cho thấy da kề da ngay sau sinh, mẹ và trẻ ở chung phòng và khuyến khích bà mẹ cho trẻ bú mẹ trực tiếp khi đảm bảo các nguyên tắc phòng ngừa chuẩn là an toàn và mang lại nhiều lợi ích cho trẻ sơ sinh có mẹ nhiễm COVID-19 [12].

Bài báo này chia sẻ cách thực hiện chăm sóc thiết yếu cho trẻ sinh non của bà mẹ trong khu cách ly dành cho người nghi ngờ hoặc đi về từ vùng dịch tễ COVID-19 đối với một trẻ 28 tuần 3 ngày, cân nặng lúc sinh 1035 gram tại Bệnh viện Phụ sản-Nhi Đà Nẵng. Đồng thời, trình bày tóm tắt một số thông tin quan trọng liên quan đến COVID-19 ở bà mẹ và trẻ sơ sinh.

\section{BÁO CÁO CA LÂM SÀNG}

Trẻ trai, 28 tuần 3 ngày, cân nặng lúc sinh 1035 gram, sinh mổ vì mẹ tiền sản giật nặng tại khu cách ly Bệnh viện Phụ sản-Nhi Đà Nẵng.

Tiền sử: Sản phụ 33 tuổi, là lao động xuất khẩu tại Đài Loan, PARA 1001, con đầu 8 tuổi, sinh dự đoán 25/8/2020. Tại khu cách ly, sản phụ được khám và ghi nhận có phù, tăng huyết áp, CTG dao động nội tại kém. Sản phụ được điều trị với magnesium sulfate, nifedipine, dopegyt, dexamethasone 3 ngày nhưng kém đáp ứng, nên được chỉ định đình chỉ thai nghén.

Chuẩn bị nhân lực: Ê kíp mổ lấy thai gồm 2 bác sĩ sản, 1 phụ mổ, 1 nữ hộ sinh đón trẻ; Gây mê hồi sức: 1 bác sĩ, 1 kỹ thuật viên; Hồi sức sơ sinh: 1 bác sĩ, 1 điều dưỡng có kỹ năng hồi sức sơ sinh nâng cao.

Giải thích cho bà mẹ và gia đình: Trao đổi kế hoạch chăm sóc bà mẹ và trẻ ngay sau sinh và trong những ngày đầu sau sinh, các biện pháp phòng hộ cá nhân dành cho bà mẹ nhằm phòng ngừa lây nhiễm SARS-CoV-2 gồm rửa tay và mang khẩu trang y tế; thảo luận về tầm quan trọng của việc thực hiện da kề da, chăm sóc Kangaroo và nuôi con bằng sữa mẹ.

Chuẩn bị phương tiện tại khu cách ly: Lý tưởng là có phòng sinh và phòng mổ tại khu cách ly hoặc trong 1 phòng có bàn sinh/bàn mổ nếu nguồn lực 
hạn chế; khu vực hồi sức sơ sinh với giường sưởi được đặt cách bàn sinh 2 mét với đầy đủ dụng cụ hồi sức, hộp mica hồi sức trẻ để tránh vấy nhiễm giọt bắn, nguồn khí oxy, khí nén; Phòng hồi sức sau mổ: 2 giường hỗ trợ tư thế Kangaroo, lồng ấp, máy thở, máy monitor và 1 phòng cho nhân viên theo dõi qua monitor khi vẫn mặc đồ bảo hộ.

Chăm sóc trẻ ngay sau sinh: Phẫu thuật viên nhanh chóng lau khô, đánh giá thấy trẻ không thở, tiến hành kẹp cắt rốn một thì và chuyển sang giường hồi sức. Sau khi thông khí áp lực dương qua mặt mạ, trẻ có nhịp tự thở tăng dần, nhịp tim $>100$ lần/phút. Trẻ được hỗ trợ CPAP oxy 21\%, PEEP $6 \mathrm{cmH}_{2} \mathrm{O}$, sau đó được đặt da kề da với mẹ trong suốt 90 phút đầu sau sinh. Trẻ được đưa vào lồng ấp lấy mẫu xét nghiệm, đặt đường truyền tĩnh mạch trong khoảng 30 phút rồi đưa trở lại tư thế Kangaroo với mẹ. Tại thời điểm 120 phút tuổi, nhiệt độ của trẻ là $36,6^{\circ} \mathrm{C}$. Trẻ được nuôi dưỡng dịch truyền tĩnh mạch và $0,5-1 \mathrm{ml}$ sữa mẹ vắt ra trong ngày đầu sau sinh. Trẻ được thực hiện xét nghiệm SARS-CoV-2 vào ngày thứ 7 và 12 sau sinh. Kết quả mẹ và trẻ đều âm tính.

Diễn tiến của trẻ trong 2 tuần đầu sau đẻ: Trẻ được hỗ trợ hô hấp với thở máy chế độ CPAP oxy $21 \%$, chăm sóc theo phương pháp Kangaroo, nhiệt độ ổn, không có cơn ngưng thở dài, nhịp tim 130-150 lần/phút, sữa mẹ ruột tăng mỗi 20$30 \mathrm{ml} / \mathrm{kg} / \mathrm{ngày}$, trẻ phù nhẹ 2 ngày đầu, kháng sinh cho nhiễm trùng sơ sinh ngưng sau 6 ngày, vàng da ngưỡng chiếu đèn, đường máu ổn định. Trẻ tăng cân từ ngày thứ 5 sau sinh và đạt cân nặng lúc sinh thời điểm 10 ngày tuổi, ăn sữa mẹ hoàn toàn ngày thứ 12 với $185 \mathrm{ml} / \mathrm{kg} / \mathrm{ngày}$. CPAP ngưng sau 5 tuần. Trẻ xuất viện lúc 59 ngày tuổi, tuổi hiệu chỉnh là 37 tuần, cân nặng 1800 gram. Đến ngày $27 / 10 / 2020$ trẻ được 140 ngày tuổi, tuổi hiệu chỉnh 2 tháng tuổi, cân nặng 5000 gram, bú mẹ hoàn toàn.

Cách bố trí nhân lực chăm sóc mẹ và trẻ tại phòng cách ly

- Người nhà: 1 người chăm sóc

- Nhân viên: 1 điều dưỡng chăm sóc bà mẹ trong vòng 6 giờ sau mổ; 3 nữ hộ sinh chăm sóc bà mẹ đồng thời theo dõi sản phụ khác trong khu cách ly; 3 điều dưỡng nhi sơ sinh thay phiên nhau hỗ trợ bà mẹ và người nhà chăm trẻ sơ sinh, hướng dẫn cách chăm sóc trẻ cho bà mẹ.Thời gian làm việc của nữ hộ sinh và điều dưỡng được chia làm 2 ca: ca 1 từ 7 giờ 30 đến 17 giờ, ca 2 từ 17 giờ -7 giờ 30,1 ca ra trực nghỉ 24 giờ.

- Bác sĩ sơ sinh và sản khám 1-2 lần/ngày và khám ngay khi cần thiết.

- Chăm sóc trẻ: Trong 2 ngày đầu sau sinh, điều dưỡngtheo dõi trẻ từ khi chuyển phòng hồi sức sau mổ, nghỉ 30-60 phút buổi sáng, trưa và tối khi điều đưỡng thay đồ bảo hộ, ra ngoài ăn uống, vệ sinh cá nhân, trong thời gian này nữ hộ sinh hỗ trợ theo dõi trẻ. Khi trẻ ổn định, điều dưỡng ở tại phòng bên cạnh theo dõi qua monitor, vẫn mặc đồ bảo hộ. Ngày thứ 3 , mỗi 2 giờ, điều dưỡng vào hỗ trợ bà mẹ cho trẻ ăn khoảng 20-30 phút. Từ ngày 4, mẹ tự chăm sóc trẻ toàn diện, trẻ được thực hiện Kangaroo chủ yếu với mẹ, mỗi 4 giờ, điều dưỡng vào đánh giá trẻ khoảng 15-30 phút. Sau ngày 7, mỗi 4-6 giờ điều dưỡng vào đánh giá trẻ 1 lần trong khoảng 15-30 phút, sau đó thay đồ bảo hộ ra ngoài. Khi thực hiện chăm sóc, y lệnh điều trị, thời gian ở phòng bệnh khoảng 40-60 phút.

- Chăm sóc bà mẹ: Trong 6 giờ đầu sau mổ, đo huyết áp mỗi 30-60 phút/lần. Sau 6 giờ, nữ hộ sinh đánh giá bà mẹ 2 lần/ngày cùng lúc chăm sóc các sản phụ khác trong khu cách ly, đồng thời thực hiện y lệnh dịch truyền và thuốc cho mẹ.

- Khi ra bên ngoài khu cách ly, nhân viên y tế theo dõi, hướng dẫn bà mẹ và trẻ qua màn hình, micro và loa hoặc gọi điện thoại trực tiếp và tiếp cận khi cần.

\section{BÀN LUẬN}

Tỷ lệ mắc và thể lâm sàng của bệnh COVID-19 ở trẻ em dường như nhẹ hơn ở người lớn. Theo báo cáo từ Trung Quốc, đến cuối tháng 2 năm 2020, trong số 55.924 trường hợp xác định bệnh COVID-19 có $2,4 \%$ trường hợp là người trẻ dưới 
19 tuổi và chỉ 2,5\% trong số trường hợp dưới 19 tuổi biểu hiện nặng. Trong báo cáo này, chưa có ghi nhận tử vong ở trẻ em, ghi nhận một trường hợp trẻ nặng phải nhập viện hồi sức tích cực nhưng các bác sĩ vẫn chưa khẳng định diễn biến nặng do COVID-19 hay do bệnh lý nền.

Nghiên cứu tổng hợp từ báo cáo khoa học ở nhiều quốc gia từ tháng 1 đến đầu tháng 5 năm 2020, với gần 7500 trẻ em trong đó có 25 trẻ sơ sinh nhiễm SARS-CoV-2 cho thấy đa phần trẻ có triệu chứng vừa và nhẹ, chỉ khoảng $2 \%$ trẻ cần nhập vào đơn vị hồi sức tích cực và tỷ lệ tử vong là $0,08 \%$ [10]. Trẻ sơ sinh nhiễm SARS-CoV-2 được báo cáo có thể có các triệu chứng sốt, li bì, ho, thở nhanh, thở gắng sức, ngưng thở, nôn, tiêu chảy và bú kém. Một số triệu chứng rất khó phân biệt với các bệnh lý thường gặp ở trẻ sơ sinh như chậm hấp thu dich phế nang, bệnh màng trong, và nhiễm trùng sơ sinh [13].

Tại Việt Nam, tính đến thời điểm ngày 5/12/2020, có 71 trường hợp là trẻ em dưới 16 tuổi và chưa có ca nặng nào được báo cáo[14].

Phân tích tổng hợp 108 phụ nữ mang thai nhiễm COVID-19, 20\% nhiễm giai đoạn sớm của thai kỳ, $79 \mathrm{ca}(92 \%)$ sinh mổ và 7 ca sinh thường, 3 ca nhập đơn vị chăm sóc tích cực, không bà mẹ nào tử vong. Có 2 trẻ tử vong, 1 trong thời kỳ bào thai và 1 trẻ 34 tuần 5 ngày tử vong lúc 9 ngày tuổi, xét nghiệm dịch hầu họng âm tính với SARS-CoV-2. Nhiều trung tâm y tế ở Trung Quốc thực hiện mổ đẻ, cách ly trẻ ngay sau sinh nhằm phòng ngừa sự lây truyền cho trẻ nhưngvẫn chưa có bằng chứng rằng thực hành này có lợi cho bà mẹ và trẻ sơ sinh. Tại Vũ Hán, 33 trẻ sơ sinh con của bà mẹ nhiễm COVID-19, $90 \%$ sinh mổ, cách ly khỏi mẹ và uống sữa công thức[15]. Có 3 trẻ (9\%) đã nhiễm COVID-19, không trẻ nào cần phải điều trị tại đơn vị hồi sức tích cực.

Trẻ sơ sinh cực non đầu tiên nhiễm COVID-19 được báo cáo tháng 3-2020 là trẻ 26 tuần 4 ngày, cân nặng 980 gram sinh ra từ Bệnh viện Sain Luc, Bỉ. Trẻ được hỗ trợ thông khí áp lực dương liên tục, bơm surfactant. Trẻ ăn sữa mẹ sau khi xét nghiệm mẫu sữa mẹ âm tính với SARS-CoV-2. Da kề da với mẹ 1 lần duy nhất vào ngày thứ 6 sau sinh, sau đó mẹ sốt cao, dương tính với SARSCoV-2 nên ngưng da kề da [16], bệnh phẩm dịch mũi họng của trẻ ngày thứ 7 sau sinh cho kết quả dương tính với SARS-CoV-2 và trẻ xét nghiệm âm tính sau 14 ngày. Sự lây nhiễm trong trong bệnh viện đã được báo cáo ở Romania, 10 trẻ sơ sinh được xét nghiệm dương tính với SARS-CoV-2 dù mẹ âm tính, gợi ý có thể trẻ đã nhiễm từ nhân viên y tế chăm sóc trực tiếp[17].

Diễn tiến bệnh của trẻ sơ sinh bị nhiễm SARSCoV-2 thường là không nghiêm trọng. Trong khi đó, bằng chứng cho thấy trẻ có thể bị nhiễm SARS-CoV-2 ngay cả khi trẻ bị cách ly và bú sữa công thức, chứng tỏ rằng việc cách ly thường quy trẻ là không cần thiết và chưa phải là một biện pháp ngăn ngừa bệnh tối ưu trong khi tác hại của việc chia cách mẹ con, trẻ không được bú sữa mẹ trong những giờ đầu sau sinh có thể tăng nguy cơ bệnh tật và tử vong $[11,18]$. Nhiều nghiên cứu cũng cho thấy gói can thiệp chăm sóc sơ sinh thiết yếu sớm đã giảm hơn $30 \%$ tỉ lệ trẻ cần nhập vào các đơn vị hồi sức tích cực sơ sinh [19, 20]. Trẻ bú mẹ hoàn toàn trong 6 tháng đầu giảm nguy cơ tử vong do tiêu chảy 5-10 lần và viêm phổi 3-15 lần. Bú sữa mẹ đến 24 tháng tuổi giảm tử vong do tiêu chảy và viêm phổi 2 lần [21, 22].

Hơn nữa bà mẹ nhiễm SARS có thể có kháng thể IgM trong máu vào ngày thứ 3-6 và lgG từ ngày thứ 8. Do đó kháng thể từ mẹ có thể sẽ truyền qua nhau thai để giúp trẻ chống lại virus xâm nhập hoặc giảm độ nghiêm trọng của bệnh. Kháng thể cũng có thể truyền qua sữa mẹ và giúp bảo vệ trẻ. IgA được phát hiện tiết ra trong sữa mẹ của những bà mẹ bị nhiễm COVID-19 trước đó. Mặc dù sức mạnh và độ bền của slgA phản ứng với COVID-19 vẫn chưa được xác định, nhiều thành phần hoạt tính sinh học được xác định trong sữa mẹ không chỉ bảo vệ chống nhiễm trùng mà còn cải thiện sự phát triển nhận thức thần kinh và hệ miễn dịch của trẻ [23]. Sữa mẹ cũng chứa những hoạt chất sinh học, cytokines 
và HMO (Human milk oligosaccharides) có thể ức chế virus xâm nhập vào tế bào[24]. Các nghiên cứu cũng cho thấy sữa mẹ làm giảm nguy cơ bệnh nhiễm RSV nặng [25] và giảm tần suất mắc cảm cúm thông thường ở trẻ nhũ nhi [26]. Bằng chứng khoa gần đây cho thấy, sữa bà mẹ nhiễm COVID-19 có chứa kháng thể đặc hiệu kháng lại SARS-CoV-2. Nghiên cứu ở thành phố New York trên 116 bà mẹ nhiễm SARS-CoV-2 và 120 trẻ sơ sinh của các bà mẹ này cho thấy tất cả trẻ đều có xét nghiệm SARS-CoV-2 trong vòng 24 giờ đầu sau sinh âm tính. Có 82 trẻ được theo dõi đến 5-7 ngày tuổi, 68 trẻ được nằm chung phòng với mẹ. Tất cả bà mẹ đều được cho con bú, 79 trẻ xét nghiệm vào 5-7 ngày và đều cho kết quả âm tính, 72 trẻ được xét nghiệm vào ngày 14 và kết quả cũng âm tính, không có trẻ nào có triệu chứng lâm sàng của COVID-19[12].

Do đó, cách ly trẻ sơ sinh và mẹ chỉ nên thực hiện nếu mẹ trong tình trạng nặng, không thể chăm sóc cho trẻ hoặc trẻ có đủ tiêu chuẩn cần nhập vào hồi sức tích cực [27]. Hướng dẫn xử trí lâm sàng COVID-19 ngày 27/5/2020 của WHO khuyến cáo chăm sóc thiết yếu sớm nên thực hiện dù mẹ có hay không dương tính với SARSCoV-2 [28]. Cho đến nay tại Việt Nam đã có hai bà mẹ dương tính với SARS-CoV-2 sinh con. Một trẻ ở Đà Nẵng đã được thực hiện da kề da ngay sau sinh và bú sữa mẹ, trẻ hoàn toàn khỏe mạnh và xét nghiệm SARS-CoV-2 âm tính.

Trường hợp của chúng tôi, bà mẹ xét nghiệm SARS-CoV-2 âm tính nhưng do đi về từ vùng dịch tễ nên vẫn còn trong giai đoạn cách ly. Trẻ được hồi sức theo đúng quy trình chăm sóc sơ sinh thiết yếu sớm, được hỗ trợ CPAP do nguy cơ bệnh màng trong cao, việc thực hiện chăm sóc Kangaroo khi trẻ ổn định sau sinh góp phần cải thiện hô hấp cho trẻ, giảm tỷ lệ thông khí xâm lấn và nhu cầu bơm surfactant. Chăm sóc Kangaroo giúp tăng tỷ lệ bú mẹ và bú mẹ hoàn toàn ở trẻ sinh non hoặc nhẹ cân, giúp trẻ kiểm soát thân nhiệt hiệu quả và ổn định các dấu hiệu sinh tồn, làm giảm tần suất những cơn ngưng thở dài, nhiễm khuẩn và bệnh lý hô hấp, giúp đẩy nhanh tốc độ tăng trưởng và gắn kết tình cảm mẹ con; bà mẹ và người thân là nguồn lực an toàn và hiệu quả góp phần giảm tải công việc do sự hạn chế của nguồn nhân lực y tế trong giai đoạn dịch bệnh COVID-19 diễn ra [29, 30]. Việc trao quyền cho bà mẹ tự chăm sóc con của mình trong những trường hợp nhiễm hoặc nghi nhiễm COVID-19 khi bà mẹ khỏe hoặc có triệu chứng nhẹ, với các biện pháp phòng ngừa chặt chẽ như vệ sinh bề mặt thường xuyên, mẹ đeo khẩu trang liên tục, rửa tay trước và sau cho trẻ bú là những giải pháp phù hợp đã được Tổ chức $Y$ tế thế giới khuyến cáo.

\section{KẾT LUẬN}

Các bước chăm sóc thiết yếu sớm cho bà mẹ và trẻ sơ sinh được khuyến cáo bởi Tổ chức $Y$ tế Thế giới nên được duy trì thực hiện trong bối cảnh đại dịch COVID-19 ngay cả khi bà mẹ nghi nhiễm hoặc nhiễm COVID-19 nhằm đảm bảo các lợi ích đã được chứng minh về phòng ngừa bệnh tật và tử vong cho trẻ sơ sinh và bà mẹ. Bên cạnh đó, việc tuân thủ quy trình chuẩn phòng ngừa lây nhiễm theo quy định của Bộ $Y$ tế là quan trọng. Việc bố trí nguồn lực gồm con người, trang thiết bị, cần được lên kế hoạch cụ thể, chuẩn bị đầy đủ và sẵn sàng nhằm giảm thiểu nguy cơ lây nhiễm, đồng thời sử dụng nguồn nhân lực hợp lý nhất trong bối cảnh dịch bệnh.

\section{TÀI LIỆU THAM KHẢO}

1. Allotey J, Stallings $E$, Bonet $M$, Yap $M$, Chatterjee $S$, Kew T, et al. Clinical manifestations, risk factors, and maternal and perinatal outcomes of coronavirus disease 2019 in pregnancy: living systematic review and meta-analysis. BMJ (Clinical research ed). 2020; 370: m3320.

2. Zhu $H$, Wang $L$, Fang $C$, Peng $S$, Zhang $L$, Chang G, et al. Clinical analysis of 10 neonates born to mothers with 2019-nCoV pneumonia. TransI Pediatr. 2020;9(1): 51-60. 
3. Petra Zimmermann NC. Coronavirus Infections in Children Including COVID-19. An Overview of the Epidemiology, Clinical Features, Diagnosis, Treatment and Prevention Options in Children. Pediatr Infect Dis J. 2020;(Epub ahead of print).

4. Deniz M, Tezer H. Vertical transmission of SARS CoV-2: a systematic review. The journal of maternal-fetal \& neonatal medicine: the official journal of the European Association of Perinatal Medicine, the Federation of Asia and Oceania Perinatal Societies, the International Society of Perinatal Obstet. 2020:1-8.

5. Shen K-L, Yang Y-H. Diagnosis and treatment of 2019 novel coronavirus infection in children: a pressing issue. World Journal of Pediatrics. 2020.

6. Chen H, Guo J, Wang C, Luo F, Yu X, Zhang $\mathrm{W}$, et al. Clinical characteristics and intrauterine vertical transmission potential of COVID-19 infection in nine pregnant women: a retrospective review of medical records. Lancet. 2020.

7. Wang L, Shi Y, Xiao T, Fu J, Feng X, Mu D, et al. Chinese expert consensus on the perinatal and neonatal management for the prevention and control of the 2019 novel coronavirus infection (First edition). Annals of translational medicine. 2020; 8(3): 47.

8. Lee EK, Kim WD, Lee DW, Lee SA. Management of the first newborn delivered by a mother with COVID-19 in South Korea. Clinical and experimental pediatrics. 2020.

9. World Health Organization. Report of the WHO-China Joint Mission on Coronavirus Disease 2019 (COVID-19)2020 16 April 2020. Available from: https://www.who.int/publications-detail/ report-of-the-who-china-joint-mission-oncoronavirus-disease-2019-(covid-19).

10. Liguoro I, Pilotto C, Bonanni M, Ferrari ME, Pusiol A, Nocerino A, et al. SARS-COV-2 infection in children and newborns: a systematic review. European journal of pediatrics. 2020; 179(7): 1029-46.
11. Tran HT, Nguyen PTK, Huynh LT, Le CHM, Giang HTN, Nguyen PTT, et al. Appropriate care for neonates born to mothers with COVID-19 disease. Acta Paediatr. 2020.

12. Salvatore CM, Han JY, Acker KP, Tiwari $P$, Jin J, Brandler $M$, et al. Neonatal management and outcomes during the COVID-19 pandemic: an observation cohort study. The Lancet Child \& adolescent health. 2020.

13. CDC. Evaluation and Management Considerations for Neonates At Risk for COVID-19 2020.

14. Bộ Y tế. Trang thông tin về dịch bệnh viêm đường hô hấp cấp Covid 19. Available at: https:// ncov.moh.gov.vn/. Accessed 16/03/2020.

15. Zeng L, Xia S, Yuan W, Yan K, Xiao F, Shao J, et al. Neonatal Early-Onset Infection With SARSCoV-2 in 33 Neonates Born to Mothers With COVID-19 in Wuhan, China. JAMA Pediatr. 2020.

16. Piersigilli $F$, Carkeek $K$, Hocq $C$, van Grambezen B, Hubinont $C$, Chatzis $O$, et al. COVID-19 in a 26-week preterm neonate. The Lancet Child \& adolescent health. 2020; 4(6): 476-8.

17. Diana Salceanu. $10 \mathrm{New}$ Born From Timisoara Infected With COVID-19 In The Maternity Ward. Their Moms Tested Negative. Criminal File Opened202016 April 2020. Available from: https://www.romaniajournal.ro/societypeople/10-new-born-from-timisoara-infectedwith-covid-19-in-the-maternity-ward-theirmoms-tested-negative-criminal-file-opened/.

18. Group NS. Timing of initiation, patterns of breastfeeding, and infant survival: prospective analysis of pooled data from three randomised trials. Lancet Glob Health. 2016;4(4): e266-75.

19. Schneider LW, Crenshaw JT, Gilder RE. Influence of Immediate Skin-to-Skin Contact During Cesarean Surgery on Rate of Transfer of Newborns to NICU for Observation. Nurs Womens Health. 2017;21(1): 28-33. 
20. Tran. HT, Mannava. P, Murray. J, Nguyen. PT, Tuyen. LTM, Tuan. HA, et al. Early essential newborn care is associated with reduced adverse neonatal outcomes in a tertiary hospital in Da Nang, Viet Nam: A pre- post- intervention study. EClinicalMedicine. 2018;6:51-8.

21. Fischer Walker CL, Rudan I, Liu L, Nair H, Theodoratou E, Bhutta ZA, et al. Global burden of childhood pneumonia and diarrhoea. Lancet. 2013;381(9875):1405-16.

22. Lamberti LM, Zakarija-Grković I, Fischer Walker CL, Theodoratou E, Nair H, Campbell $\mathrm{H}$, et al. Breastfeeding for reducing the risk of pneumonia morbidity and mortality in children under two: A systematic literature review and meta-analysis. BMC Public Health. 2013; 13(SUPPL.3).

23. Fox A, Marino J, Amanat F, Krammer F, Hahn-Holbrook J, Zolla-Pazner S, et al. Robust and Specific Secretory IgA Against SARSCoV-2 Detected in Human Milk. iScience. 2020;23(11):101735.

24. Grabarics M, Csernak O, Balogh R, Beni S. Analytical characterization of human milk oligosaccharides - potential applications in pharmaceutical analysis. J Pharm Biomed Anal. 2017; 146: 168-78.

25. Jang MJ, Kim YJ, Hong S, Na J, Hwang JH, Shin SM, et al. Positive Association of Breastfeeding on Respiratory Syncytial Virus
Infection in Hospitalized Infants: A Multicenter Retrospective Study. Clinical and experimental pediatrics. 2020.

26. Munblit D, Treneva M, Peroni DG, Colicino S, Chow LY, Dissanayeke S, et al. Immune Components in Human Milk Are Associated with Early Infant Immunological Health Outcomes: A Prospective Three-Country Analysis. Nutrients. 2017; 9(6).

27. Royal College of Obstetricians and Gynaecologists. Coronavirus (COVID-19) Infection in Pregnancy. Available at: https://www.rcog.org.uk/ globalassets/documents/guidelines/coronaviruscovid-19-virus-infection-in-pregnancy-2020-03-09. pdf. Accessed 12/03/2020.

28. World Health Organization. Clinical management of COVID-19 Interim guidance 27 May 202020/12/2020 20/12/2020]. Available from: https://www.who.int/publications/i/item/ clinical-management-of-covid-19.

29. Chan GJ, Valsangkar B, Kajeepeta S, Boundy EO, Wall S. What is kangaroo mother care? Systematic review of the literature. Journal of global health. 2016;6(1):010701-.

30. Charpak N, Tessier R, Ruiz JG, Hernandez JT, Uriza F, Villegas J, et al. Twenty-year follow-up of kangaroo mother care versus traditional care. Pediatrics. 2017;139(1). 